\title{
Reflections on Heidegger: Performing Translations in Active Space Environments
}

\author{
Lisa Naugle and John Crawford
}

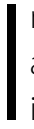

n recent years, digital media technologies have expanded our ability as performing artists to transcend the physical boundaries of where and how individuals and groups interact. Ubiquitous screen-based modalities such as Skype, Facebook, and Twitter invite us to consider the pervasiveness of technology as well as the transformative aspects of interacting through electronic media in real time. In Martin Heidegger's 1954 essay, "The Question Concerning Technology," he challenges us to consider the impact of technology "in the realm where revealing and unconcealment take place." His discussion of how human interaction with technology involves both a "danger" and a "saving power" provides us with a context to understand what happens when we bring the "machines and apparatus" of digital media into contact with live dancing bodies. In this paper, we reflect upon experiences drawn from bringing choreographer Lisa Naugle's explorations of structured improvisation into contact with intermedia artist John Crawford's investigation of interactive environments using the Active Space system. ${ }^{2}$

For almost twenty years we have engaged in collaborative research using digital media within dance, deriving real-time imagery from movement. We create interactive media and performance environments using an evolving collection of custom, real-time media objects called Active Space. These environments also may incorporate optical motion capture and other advanced technologies for representing human movement. While we believe that the essence of dance can never be captured or fully reproduced through any technology, digitally mediated spaces are useful because they allow us to synthesize multiple representations and to interact with these representations in space and in time. Embodied relationships between illusion and memory can create cognitive pathways for increasingly rich dance-media interactions.

For example, in Ootoo (2006), created with choreographer Ted Warburton, we deal with themes of illusion, identity, and multiplicity. Student dancers in two locations (Irvine and Santa Cruz, California) simultaneously interact with projections created by the Active Space system, merging live video from both sites into a painterly, abstract representation of movement, accompanied by more realistic views of the dance projected on other screens in each theatre space.

In Urban Fabric: Prague (2005), created with composer Martin Gotfrit, we combine abstracted cityscape images and sounds with live narration, dance, and musical accompaniment. Entering the stage space as a dancer, I (Naugle) am aware that where I locate myself is critical to being seen by the video cameras as well as by the audience. Once I find the location where all cameras, audience and other on-stage performers can see me, I begin to articulate small movements on a variety of levels, "testing" how much effort I need to expend for the system to activate and respond to me. In the moment of moving, 
I become more present, realizing the visual landscape projected on the screen behind me requires me to make internal notes. My proprioceptive skills tell me when I am out of camera range, and how long to wait until the mirror image of body disappears or changes into something else. In my role as an interactive performer I am challenged to be fully present in each moment, drawing a link between recognizable images, abstractions and my improvised dancing. The visual and sound elements performed live by Crawford and Gotfrit are new to me and I must pace my evolving relationship with these elements in an arc for the piece that connects with a live audience. The dance itself is fleeting but the images of my body are persistent and repeated on screen. Any part of my choreography can be arrested in time and framed in a layered montage of metaphors and abstractions. My inner voice hooks into a particular theme or performance dynamic and my movement follows. Long durations of stillness provide counterpoints while media elements collide, giving the appearance that nothing is complete. The Active Space system and I work together to generate imagery that converses with itself. My chance to build up a particular moment mobilizes a consciousness of multiple dimensions interacting and giving way to new possibilities for meaning.

Drawing on Heidegger's formulation, we posit that the interactive experience pushes the potential of enframing in our Active Space media objects, which include systems for multi-channel live video and audio processing, generative animation, musical composition, media base storage/retrieval, and high bandwidth networking. Techniques for locating oneself in multi-dimensional spaces have long been employed on the stage and in the studio. To be fully present in a responsive media environment, a performing artist must become available to an increased level of awareness, knowing that even the smallest movement can be amplified, mediated, translated and presented many miles away from the actual place and time of performance. Furthering Heidegger's notion of enframing, the dancer becomes an active participant to create frames of representation and continues to be part of the enframing process as movement material is captured and re-presented. For example, Active Space motion tracking objects can perform real-time sensing and analysis of location, speed, duration and various other characteristics of dancers' movement, and the results of this analysis may be used to synthesize video and audio materials. This occurs not only in the same location and the current time, but also may involve artifacts, which are presented in remote environments or at a future time.

In creating an Active Space performance, installation, or workshop, we base our process on the understanding that exploratory research is a way of "bringing-forth" and a necessary first step toward developing knowledge and skill. We attend to language and watch the descriptors emerge, learning how embodied interaction actually evolves from one kind to another through movement, voice, and other forms of dynamic expression. Looking for the "essence" of interactions with technology and affirming body-centered practices, we develop a series of compositional and improvisational approaches to stage space, screen space, and sound space. As the technological apparatus interfaces with human bodies, we aspire to build systems with the potential to evolve through trial and error, remaining open to technological limitations while seeking opportunities for intuitive learning.

The interplay between improvisational and compositional elements is of particular interest when we combine motion tracking with motion capture. Motion tracking involves real-time sensing and analysis of location, speed, duration, and various other characteristics 
of movement. The results of this analysis are fed to a computer system that generates video and audio in response to the movement. Motion capture is the technique of sampling movement in 3D space and creating graphical representations of that movement. Typical applications of motion capture tend to produce realistic animations, but the aesthetic focus of our Active Space work extends beyond realism to explore non-linear associations, along with issues of embodiment and reflexivity.

Heidegger's concerns with the dangers of "enframing" and his notion of "stockpiling" are particularly relevant in the performance context, where dancers can sometimes feel that the technology on stage is "happening to them," or "out of their control." Situations where performers influence technical elements in a direct, immediate way have the potential to challenge such perceptions, creating opportunities to generate new internal imagery and proprioceptions to enhance motivation and stimulate interactions between the performers themselves as well as with the technical elements. Dancers in mediated environments develop increasingly sophisticated vocabularies of responses and apply them to create contexts and mechanisms for communication. The media system itself becomes a message, or a series of messages, an embodied sequence of codes, exchanged between performers and with audiences.

To date, we have worked with dancers, choreographers, musicians, composers, scenic and lighting designers, directors, actors, visual artists, animators, filmmakers, interface designers, computer scientists, engineers, architects, and others intrigued by issues of embodiment, technology and interactive experience. A collaborative research approach encourages all participants to explore a variety of dance/media approaches. Such experiences can contribute to a convergence between artistic practice and emerging technology.

\section{References}

emptLab: Embodied Media + Performance Technology Lab. http://embodied.net/active-space. August 18, 2011.

Heidegger, Martin. "The Question Concerning Technology." The Question Concerning Technology and Other Essays. Translated by W. Lovitt. New York: Harper Torchbooks, 1977. 3-35.

\section{Notes}

1. Heidegger, "The Question," 13.

2. Developed by intermedia artist and software designer John Crawford in association with choreographer Lisa Naugle and composer Martin Gotfrit. See: http://embodied.net/active-space. 